\title{
Isolated FEV1 Reduction among Stone Crusher Workers- A Possible Indicator of Obstructive Pulmonary Disease
}

\author{
Barun $\mathrm{M}^{1,2}$, Paraksh $\mathrm{L}^{1}$, Lava $\mathrm{S}^{2}$ and Sunil $\mathrm{D}^{1 *}$ \\ ${ }^{1}$ Department of Clinical Physiology, College of Medicine, Nepalese Army Institute of \\ Health Sciences, Nepal \\ ${ }^{2}$ Department of Clinical Physiology, Maharajgunj Medical Campus, Nepal
}

*Corresponding author: Sunil Dhungel, Department of Clinical Physiology, College of

\section{Research Article}

Volume 4 Issue 3

Received Date: May 21, 2019

Published Date: June 19, 2019

DOI: $10.23880 / \mathrm{ijbp}-16000164$

Medicine, Nepalese Army Institute of Health Sciences, Kathmandu, Nepal, Email: sunil.dhungel@nsnnepal.org

\section{Abstract}

Introduction: Most of the occupational lung diseases are associated with workers exposed to aerosols in the form of dust, fumes and gases within workplace. The stone crusher industry are one of the main source of emission of dust particles in ambient air. The workers engaged in stone processing and quarrying are at risk of developing impaired lung functions due to direct exposure with high concentrated of dust particulates. Therefore, it is important to study the pulmonary function status of this group of workers.

Objective: The aims of this study is to compare the pulmonary function among the individuals (workers) exposed to workplace dust and those not exposed residing population nearby stone crusher unit by spirometric evaluation includes forced vital capacity (FVC), forced expiratory volume in first second (FEV1), ratio of forced expiratory volume in first second and forced vital capacity (FEV1/FVC).

Methodology: Out of 74 participants, 37 (50\%) were stone crusher workers and 37(50\%) were non-workers. Among total participate $54.05 \%$ were female and $45.95 \%$ were male with mean \pm SD age in years of participate was $27.87 \pm 4.50$. The participants performed spirometry in the sitting position by open circuit method. A nose clip was applied to the nose. The participants were instructed to take a full and fast breath in, seal their lips around the mouthpiece tightly and blow as hard and as fast as possible for at least six seconds. Parameters of spirometry FVC, FEV1, FEV1/FVC were collected in the form of percentage of predicted for age, sex, height, weight and ethnicity. The test were performed three times and best recording were taken for the study.

Results: On data analysis there is statistical significance in mean \pm SD FEV1 (81.08 $\pm 11.86,81.07 \pm 15.74)$, FVC 99.65 \pm 6.8 , $99.89 \pm 6.11$ ) and insignificance decrease in FEV1/FVC ratio among workers and non- workers respectively. There is high prevalence rate of respiratory illness or symptoms among stone crusher workers than non-workers. The most common symptom are rhinitis $16.2 \%$, cough $6.8 \%$, shortness of breathlessness $4.1 \%$ with wheeze $7 \%$ and tightness of chest or 


\section{International Journal of Biochemistry \& Physiology}

pain $7 \%$ among the workers than control groups who were residing at local area rhinitis $8.6 \%$, cough $6.8 \%$, shortness of breathlessness $0 \%$ with wheeze $3 \%$ and tightness of chest or pain $4 \%$ respectively.

Conclusion: Isolated FEV1 reduction among stone crusher workers may be good possible indicator of obstructive pulmonary disease. The decline in pulmonary function (FVC, FEV1, FEV1/ FVC) in stone crusher unit workers may be due to lack of awareness of dust controlling measurement and could be continuously exposure with dust particulates in workplace.

Keywords: Stone crusher workers; Obstructive pulmonary disease; FEV1; Pulmonary function test; Respiratory illness

\section{Introduction}

As a consequence of rapid urbanization and mega constructions such as road, highways, bridges, building, canals, and dam occurring rapidly each year in Nepal, a parallel increase in numbers of stone crushing industries in almost all major cities areas is taking place. Stone crushing process is a labor-intensive work that includes mining, drilling, blasting mountains and rocks, loading, hauling, crushing, screening, conveying, other handling and transfer operation [1]. Depending on the type of operation, workers are employed at different places. It is estimated that there are about 283 stone crusher units in which approximately 42,000 people are engaged throughout Nepal [2]. Most of people involved this occupation for their daily livelihood belongs to poor, uneducated and unskilled rural community.

It is known that all stone crushing processes are important source of generating huge amount of dust at working site and its surroundings. Most of stone quarries are operated at open area without taking proper safety guideline for dust management at work site. Therefore, the significant percentage of dust is also carried away to the surrounding local area by wind. The study conducted at Pammal, Tamil Nadu among 50 stone crushing units reported that there is huge amount of air pollution within the crushers and in nearby area [3].

Dust exposure in workplace has long been identified as a major cause of occupational lung disease [4]. During mining/ blasting mountain and rocks the huge amount of silica containing dust is emitted which is inhaled and deposited at different parts of respiratory system causing irritation and inflammatory lung injuries, allergic response includes allergic rhinitis, chronic cough, breathlessness, wheeze, tightness of chest and so on [5].
The particulate matter size less than $5 \mu \mathrm{m}$ can pass through the smallest bronchioles and reach the alveoli [6]. Some respiratory diseases depend on particulate matter size, shape, density. Several studies have reported that particulate matter exposure is one of the causes of various respiratory diseases, such as asthma, chronic obstructive lung disease, pneumonia, pneumoconiosis, lung cancer and skin diseases [6-9].

Therefore, prolonged and chronic exposure to huge amount of silica-containing dust in working site is responsible for causing variation in pulmonary functions due to irritation and inflammation of bronchioles and alveoli [10]. For instance in interstitial lung disease there is reduce Forced Vital Capacity (FVC) and higher air flow rate therefore FEV1 ( forced expiratory volume expelled out in first one second) exceed $80 \%$ and in obstructive lung diseases there is lower flow rate as result of high resistance and hence FEV1\% is low [11]. The different studies conducted around the globes from 2000 to 2006 particularly in Malaysia, Iran, and India showed decrease in FEV1, FVC and FEV1/FVC ratio among the stone crusher workers [12-15].

In developing and least developed countries including Nepal, worker's ill-health is probably due to unsatisfactory working environment and poor safety measures such as, masks, helmets, proper ventilation so on.

Therefore, the purpose of this study is to confirm the harmful effects of dust on pulmonary system of workers on the basis of questionnaire, Spirometric measurement and to impart awareness among workers, employers and population living around the stone crushing factories area about detrimental and hazardous effects of such airborne dust on health. 


\section{International Journal of Biochemistry \& Physiology}

\section{Limitation of Study}

Since the current study was conducted in one stone crusher factory, the sample size and the types of dust (we didn't analyze the dust compositions) emitted from a single factory (in this study) may not necessarily represent the effects of any other types (if any) of dust generated from the other stone crushers units on respiratory illness and pulmonary function tests. Additionally, during the stone crushing process, various procedures and operations are involved. Based on these operations, workers are employed at different places as per the nature of work. There may be correlations between duration, degree, size, and density of dust (particulate matter PM10 and PM2.5) exposure and development of respiratory disease which is not taken into consideration in this study. Since both groups are equally exposed to the environmental pollution, the influence of socioeconomic status and awareness are not considered in this study.

\section{Significance of Study}

Dust generated from the stone crusher units is the major contributing factor for occupational lung disease. Even though workers are conscious about the harmful effects, they are not aware of the extent and severity of these negative effects on their health and showed negligence on wearing helmets, mask and so on.

Therefore, the purpose of the study is to provide awareness among workers and employers about occupational related health-hazards and to verify the harmful effects of dust on pulmonary function.

However, adequate data on exposure assessment are still lacking in our country. Therefore, exposure data will be a crucial tool in disease prevention and can provide scientific information essential to identify which type of jobs or which specific groups of workers are at risk of developing respiratory disease

\section{Methodology}

Design of Study: This is a cross-section descriptive study.

Study Setting: This study was carried out within and around areas of Shiv Roada Factory Panauti, Kavrepalanchok, Nepal.

Study Population: This study was conducted among the workers who were occupationally exposed to dust in workplace and non-exposed people residing around the perimeter who were in-directly exposed to air pollutants of Shiva Roada Factory in Panauti, Kavrepalanchok, Nepal.

Sample Size and Technique: Out of 74 individual, 37 were workers who were working more than 1 year and 37 were occupationally non-exposed residing within area of factory. The selected individuals were interviewed and made to perform spirometry.

\section{Data Collection}

\section{Spirometric Evaluation}

The spirometric evaluation were done by MIR Spiorlab II portable desktop spirometer. Data of spirometry test were collected in the form of percentage of the predicted for the age, sex, height, weight which includes FEV1, FVC, and FEV1/FVC ratio. The data of respiratory symptoms were collected with the use of structure questionnaire, history taking and clinical examination. The study was conducted after obtaining approval from Institutional Review Board of the Institute of Medical, Maharajgunj Medical Campus.

Instruments used in this study are: MIR Spirolab II portable desktop spirometer, Questionnaire, Weighing scale, Height scale, stethoscope, sphygmonmanmeter.

\section{Clinical Examination of Respiratory System}

Before the spirometric evaluation, respiratory examinations of all subjects were carried out using standard protocol for clinical examination of respiratory system.

Inclusive Criteria: Individuals fulfilling the following criteria were included in this study age between 18 to 50 years, willing to participate, and working in stone crushing industry for more than one years.

Exclusive Criteria: Follows according to American thoracic society ATS [16]. In brief, individuals with following conditions were excluded:- Recent myocardial infarction (within previous 1 month),recent stroke, recent eye surgery, recent thoracic or abdominal surgery, hemoptysis, known thoracic, aortic or cerebral aneurysm, recent pneumothorax, uncontrolled hypertension, pulmonary embolism, chest or abdominal pain of any cause, oral or facial pain exacerbated by a mouth piece ( of spirometer), stress incontinence, dementia or confusional state and smoking. 


\section{International Journal of Biochemistry \& Physiology}

\section{Procedure}

All individual were explained about the purpose and risk of the study. The individual consent was taken before the procedure and was given 5minutes rest for physical and mental relaxation. They were requested not to have large meal, wear tight clothes, cigarette smoking, and alcohol consumption and do heavy or vigorous exercise few hours before procedure. The test was done by open circuit method according to American Thoracic Society guidelines [17]. The tests were performed three times and best recording were taken for the study.

\section{Data Analysis}

Microsoft Excel 2007 was used for data entry and Statistical Package for Social Sciences (SPSS) version 22 was used for analysis of collected data. The result were presented in the form of mean \pm standared deviation and Independent samples t-test was applied to compare the means between individuals exposed and non-exposed group. Value for probability less than $0.05(p<0.05)$ at $95 \%$ confidence interval was considered statistically significant.

\section{Results}

The parameters that were under study was expressed as mean \pm SD. Out of 74 participants, 37 (50\%) were stone crusher workers and $37(50 \%)$ were non-workers. Among total participant $54.05 \%$ were female and $45.95 \%$ were male and the age in years of participate was $27.87 \pm 4.50$.

The figure 1 shows the impact of dust on respiratory system within workplace (workers) and local area nearby (non-workers) in terms of pulmonary function test. On data analysis, it is observed that there is a statistically significant lower level of FEV1 and FVC. The figure 2 shows FEV1/FVC ratio between workers and nonworkers.

The figure 3 shows there is higher prevalence rate of respiratory illness or symptoms of rhinitis (16.2\%), cough (6.8\%), shortness of breathlessness (4.1\%) with wheeze (7\%) and tightness of chest or pain (7\%) among the workers than control groups who were residing at local area with rhinitis $8.6 \%$, cough $6.8 \%$, shortness of breathlessness $0 \%$ with wheeze $3 \%$ and tightness of chest or pain $4 \%$ respectively.

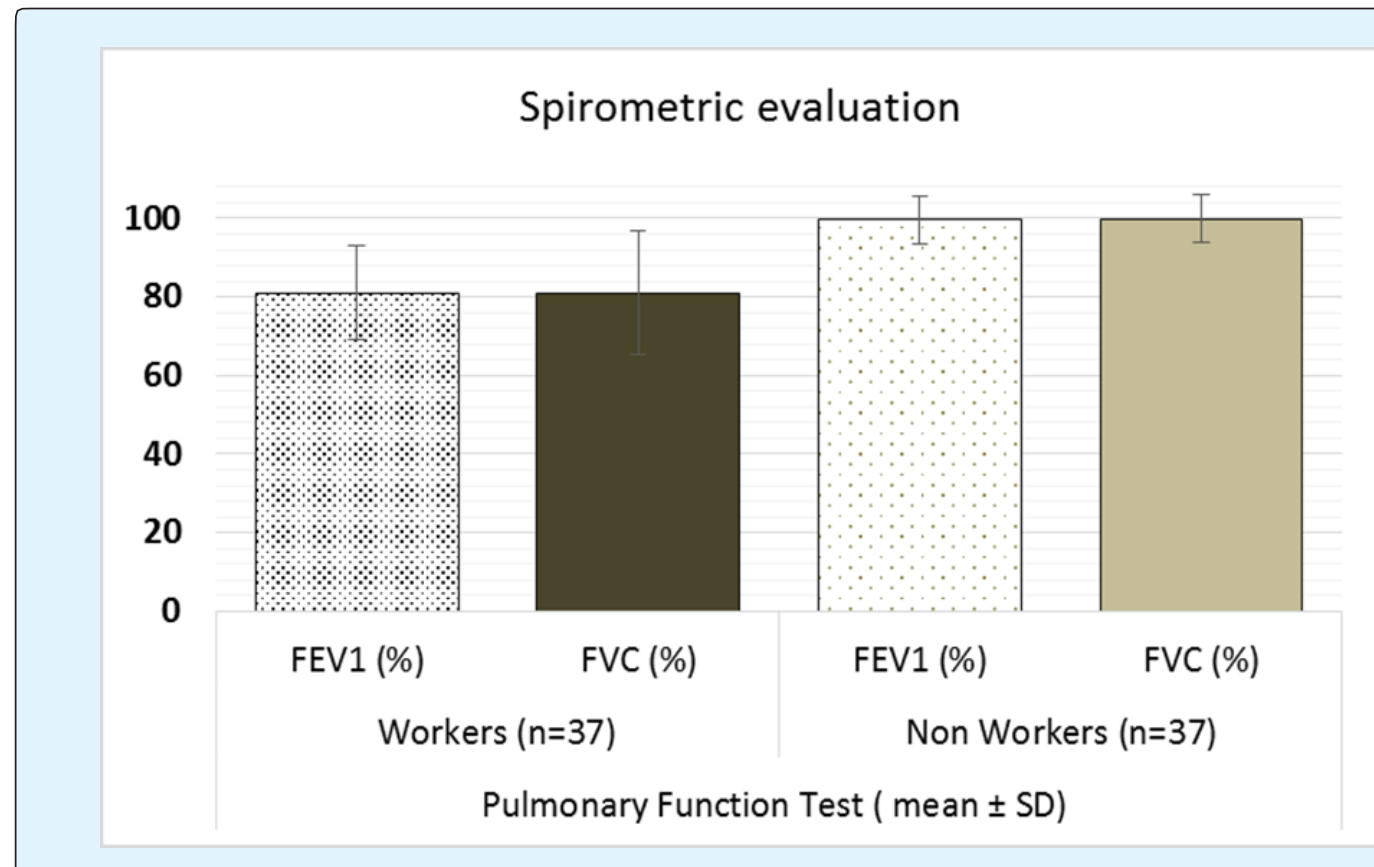

Figure 1: Illustrated FEV1 and FVC among stone crusher workers and non-workers $(p<0.05)^{*}$. 


\section{International Journal of Biochemistry \& Physiology}

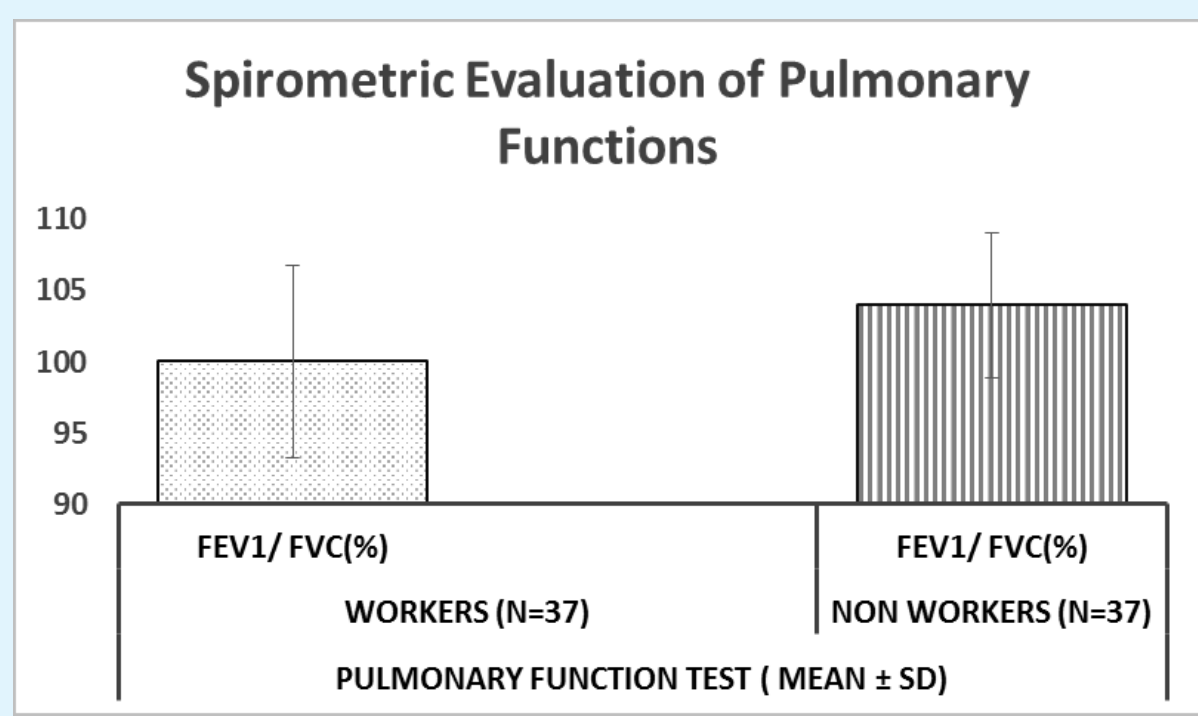

Figure 2: Showed comparison of FEV1/FVC ratio in stone crusher workers and non-workers.

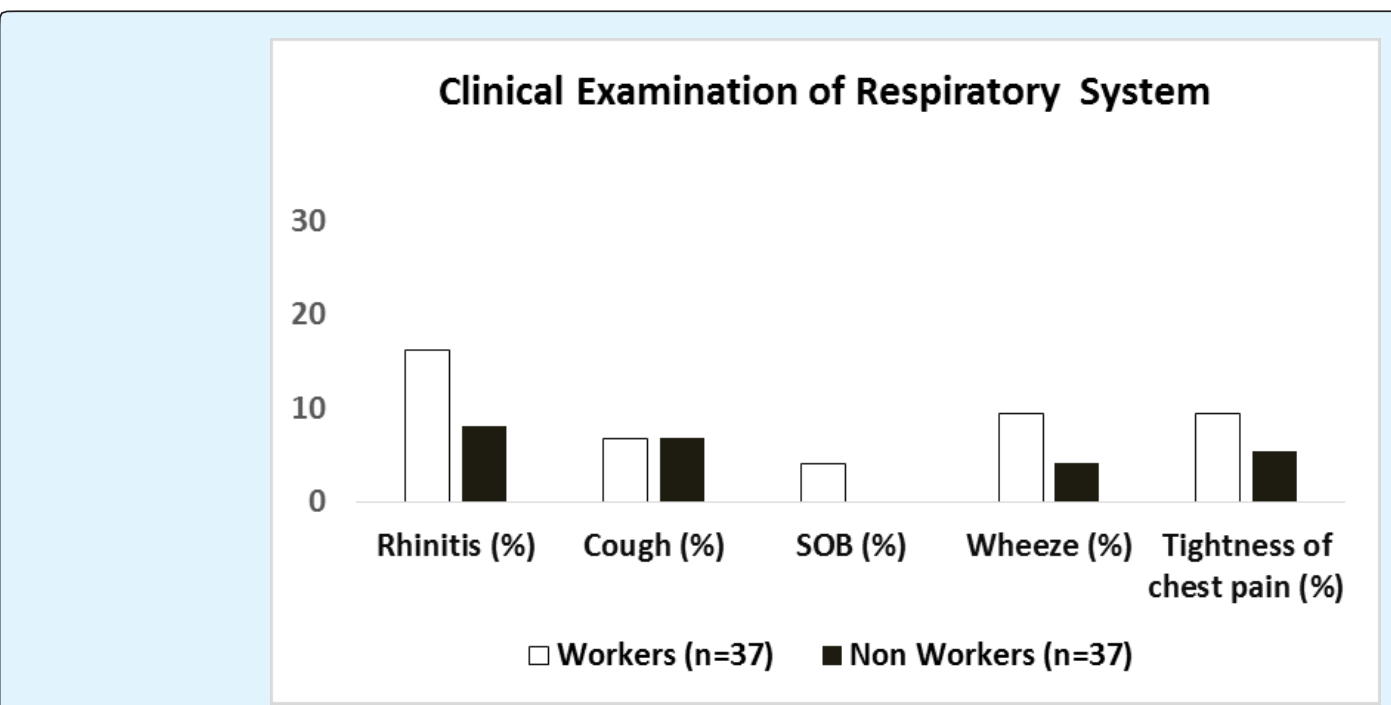

Figure 3: Showed comparison of respiratory symptoms between stone crusher workers and non-workers.

\section{Discussion}

In stone crusher units, operation workers are placed at different sectors. Most of them come from poor, illiterate background and worked without taking proper safety measurement such as, wearing mask, helmet and so on. It is well known that all stone crushing procedure are high source of generating huge amount of dust which are major cause of polluted ambient air. The workers are in more likely to expose directly to dust which is deposited in different parts of the respiratory system and cause upper and lower respiratory tract infections probably due to irritation and inflammatory reaction in respiratory mucosa resulting allergic rhinitis, cough, wheeze, shortness of breathing and so on.

The most common complaints or symptoms that are noted in workers are rhinitis, cough, tightness of chest, shortness of breath and wheeze as compared to local people (non-workers). Similar results were observed in study conducted by Nwibo, et al. in Nigeria among quarry workers of stone crushing industrial site with the most 


\section{International Journal of Biochemistry \& Physiology}

common symptoms are chest pain (47.6\%), occasional cough $(40.7 \%)$, shortness of breath $(6.5 \%)$, wheeze $(5.2 \%)$ and with significantly decrease in lung function test in FEV1 and FVC [13].

The high prevalence of respiratory symptom were noted with cough $31.9 \%$, dyspnea $41.7 \%$ and wheeze $33.3 \%$ with decrease in FVC and FEV1 among stone quarry workers in Rio de Janerio, Brazil [18].

In this study, workers were mainly from rural and agricultural background, most of them are working for the short period of time mainly in between harvest. In return of good source of economy, they are working day and night with limited precautionary measure available. Even for short duration of time, there are continuously exposed to dust and it pulmonary function may be affected. In our study we observed statistically significant decrease in FEV1, FVC and slight decrease in FEV1/FVC ratio in workers when it is compared with non-exposure groups. These findings are also in accordance with study conducted by Sheikh et al which showed a statistically significant decrease in mean \pm SD of FVC, FEV1, PEFR and FEF among stone crushers when compared to control groups and also found high prevalence of respiratory symptoms, the most common symptom reported was cough (26\%), followed by breathlessness, phlegm and chest tightness [19]. Similar study conducted in tile and ceramic factory by Dehaghan, et al. and EI Shafy, et al. reported a statistically significant decrease in pulmonary function parameters and increase in respiratory symptoms among workers in comparison to control groups [20,21].

\section{Conclusion}

This study shows that workplace dust is a major cause of respiratory morbidity and pulmonary function derangement. It is the foremost concern of developing countries, like Nepal, where stone quarrying is a means of livelihood in rural areas.

As we reported significant decrease in FEV1 and FVC among stone crusher workers as compared to nonworkers, with statistically insignificant decrease in FEV1/FVC ratio. Isolated FEV1 reduction among stone crusher workers may be a good indicator of obstructive pulmonary disease. However, there is a need of another systemic study including dust particulate determination, laboratory, thorough medical examination and comparison of different duration of exposure to dust particle on pulmonary functions test in stone crusher workers.

Our study pointed out that the stone crusher workers are vulnerable for getting dust exposure and are in high risk of lodging dust in different regions of respiratory tract. It could be due to lack of taking proper precautions such as dust reduction measurement like wearing helmet, mask, spraying water within their workplace resulting in impaired pulmonary function and increased prevalence of respiratory symptoms within short period of time.

\section{Disclaimer}

This study is carried out during my MD thesis preparation. However, the present data were not included in my submitted thesis and there is no conflict of interest.

\section{References}

1. (2009) Comprehensive Industry Document stone crushers.

2. Ajoy K, Kuntala LD (2005) Report on Artisanal and Small Mine of Nepal.

3. Sivacoumar R, Jayabalou $R$, Swarnalatha $S$, Balakrishnan K (2006) Particulate Matter from Stone Crushing Industry: Size Distribution and Health Effects. Journal of Environment Engineering 132(3): 405-414.

4. Nandini SN, Sinhnu R (1995) Impact of Quarrying and Crushing of Grantie on Environment in Bettahalsur Village with Special Reference to Socio Economic Aspects. Unpublished Angalore University, pp: 223225.

5. (2011) Occupation health problems of Stone crusher in west Bengal - A pilot study at bibhum district.

6. Anderson JO, Thundiyil JG, Stolbach A (2012) Clearing the air: a review of the effects of particulate matter air pollution on human health. J Med Toxicol. 8(2): 166175.

7. Fiordelisi A, Piscitelli P, Trimarco B, Coscioni E, Iaccarino G, et al. (2017) The mechanisms of air pollution and particulate matter in cardiovascular diseases. Heart Fail Rev 22(3): 337-347.

8. Organization WH, Elimination of Silicosis. The global Occupational Health Network. Issue No: 12-2007. 


\section{International Journal of Biochemistry \& Physiology}

9. James A Merchant (1986) Tuberculosis as an occupation disease. Occupation respiratory disease. pp: 709.

10. Churg A, Brauer M, Del Carmen Avila-Casado M, Teresa I Fortoul, Joanne L Wright (2003) Chronic exposure to high levels of particulate air pollution and small airway remodeling. Environ Health Perspect 111(5): 714-718.

11. Barreiro TJ, Perillo l (2004) An approach of interpreting spirometry. Am Fam Physician. 69(5): 1107-1114.

12. Noor H, Yap CL, Zolkepli O, Faridah M (2000) Effect of Exposure to Dust on Lung Function of Cement Factory Workers. Medical Journal of Malaysia 55(1): 51-57.

13. Bahrami AR, Mahjub H (2003) Comparative study of lung function in Iranian factory workers exposed to silica dust. Eastern Mediterranean Health Journal 9(3): 390-398.

14. Chattopadhaya BP, Gangopadhyay $\mathrm{Pk}$, Bandopadhyay TS, Alam Z (2006) Comparison of pulmonary function test abnormalities between stone crushing dust and non-exposed agricultural workers. Environment Health and Prevention Medicine 11(4): 191-198.

15. Nwibo AN, Ugwuja EI, Nwambeke NO, Emelumady OF, Ognonnaya LU (2012) Pulmonary problem among quarry workers of stone crushing industeril site at
Umugohara Ebonyi state, Nigeria. Int J Occup Environ Med 3(4): 178-185.

16. Miller MR, Crapo R, Hankinson J, Brusasco V, Burgos $\mathrm{F}$, et al. (2005) General considerations for lung function testing. Eur Respir J 26(1): 153-161.

17. Miller MR, Crapo R, Hankinson J, Burgos F, Casaburi R, et al. (2005) Standardization of spirometry. Eur Respir J 26(2): 319-338.

18. Lemele A, de Araujo AJ, Lapa e SJR, Lima Fde P, Cardoso AP, et al. (1994) Respiratroy symptoms and spirometric Test of quarry workers in Rio de Janerio. Rev Assoc Med Bras 40: 23-25.

19. Sheikh JA, Zahid AK, Sunil S, Tazeen K, Nusrat C (2018) Silica-Induced Airway Damage: A Matched Comparative Study of Pulmonary Function Test among Stone Crusher of North India. Sch J App Med Sci 6(3): 1141-1144.

20. Dehghan F, Mohammadi S, Sadeghi Z, Attarchi M (2009) Respiratory Complaints and Spiromertic Parameters in Tile and Ceramic Factory Workers. Tanaffos 8(4): 19-25.

21. EI Shafy WS, Manawil MG, EI Sherif GH (2018) Impact of Dust Exposure among Stone Quarry Workers on Ventilation Functions and Serum Level of Tumour Necrosis Factor- Alpha. Egyptian Journal of Occupatioal Medicine 42(3): 443-452. 